\title{
Validation of an Automated Enzyme Immunoassay for Interleukin-6 for Routine Clinical Use
}

\author{
Peter Fraunberger, Matthias Pfeiffer, Peter Cremer, \\ Ernst Holler, Dorothea Nagel, Isabelle Dehart, Michael \\ Thein, Autar K. Walli and Dietrich Seidel
}

Institut für Klinische Chemie, Klinikum Großhadern, LMU München, Germany

Serum levels of Interleukin-6 (IL-6), a proinflammatory cytokine, are increased in early stages of inflammatory diseases such as infection and sepsis. Assay systems which permit its measurement within a few hours and as a single measurement have not been reported so far. We therefore evaluated a now commercially available automated method for IL-6 measurement on the Cobas Core ${ }^{\circledR}$ immunological analyzer (Roche Diagnostic Systems) which enables single IL-6 measurement within about 1 hour. The automated assay correlates well with an established, manual microtiter plate assay (Biosource $\mathrm{GmbH}$ ) which uses the same antibodies and reagents $(r=0.98)$. Accuracy of the automated method was established by adding known amounts of IL-6 intemational reference preparation. Recovery of the international standard was in the range of 92$104 \%$. The automated assay had a precision of singletons below $6 \%$ and was linear up to $2800 \mathrm{pg} / \mathrm{ml}$. This automated assay provides a suitable, convenient and time saving method for measurement of IL-6 serum levels in the routine clinical laboratory.

Key words: Cytokine; Cobas Core ${ }^{\circledR}$; Automation; Inflammation; Infection; Sepsis; Routine monitoring.

\section{Introduction}

Interleukin-6 (IL-6) is a pleiotropic cytokine with a wide range of biological functions. It is implicated in the induction of fever, acute phase response, activation of $B$ and $\mathrm{T}$ lymphocytes and stimulation of hematopoesis. During inflammation IL- 6 is produced and released into the circulation in response to bacterial toxins and other cytokines by cells such as monocytes and endothelial cells. Bacterial, viral and protozoan infection have been reported to elevate serum IL-6 levels (1-3). Clinical studies in neutropenic patients indicate that IL- 6 levels are elevated within 2-3 days before clinical manifestations of inflammatory processes are evident (4). Serum levels of IL- 6 are raised earlier in the clinical course than well recognized diagnostic markers of infection such as C-reactive protein (5). High concentrations of serum IL- 6 have been reported in patients with bacterial infection, in contrast to those without infection on admission to the intensive care unit (6). Furthermore,
IL-6 levels are a sensitive parameter for early diagnosis of neonatal infection and outcome in septic patients $(2$, 7-9).

Although these studies suggest that serum levels of IL-6 may have important diagnostic value, no suitable methods have been reported so far which permit measurement of this cytokine within a few hours to utilize it as a clinical parameter in critically ill patients. In the present study we evaluated an automated immunoassay for IL-6 measurement using a coated bead enzyme-linked immunosorbant assay (ELISA) kit (Biosource GmbH, Ratingen, Germany) run on a Cobas Core ${ }^{\circledR}$ immunological analyzer (Roche Diagnostic Systems, Basel, Switzerland) which offers the possibility of measuring IL- 6 in a random access mode. Automated IL- 6 measurement on the Cobas Core ${ }^{\circledR}$ was compared with the manual method measured on microtiter plates (formerly supplied by Medgenix $\mathrm{GmbH}$, Ratingen, Germany) which uses the same antibodies and reagents (7-9).

\section{Materials and Methods}

Reagents

Coated bead ELISA kits and microtiter plate ELISA kits were supplied by Biosource GmbH (Ratingen, Germany). Both kits use monoclonal antibodies raised against distinct epitopes of recombinant IL-6. Detection antibody was labeled with horseradish peroxidase and tetramethylbenzidine was used as chromogenic substrate. The microtiter plate assay recognizes recombinant and natural glycosylated IL- 6 without interference from IL- 6 soluble receptors sIL-6R and sgp130. For anaIytical recovery studies IL- 6 standard from NIBSC (The National Institute for Biological Standards and Control, NIBSC Blanche Lane, South Mimms, Potters Bar, Herfordshire EN6 3QG, England) was employed. The vial (preparation 89/548), which contains $1 \mu \mathrm{g}$ recombinant IL- 6 and has the assigned potency of $100000 \mathrm{IU}$, was reconstituted with $1 \mathrm{ml}$ distilled water as recommended by the supplier (10). Serum without measurable IL-6 was used for further dilution.

\section{Patients and blood samples}

Residual sera from blood samples routinely submitted to the Institute of Clinical Chemistry for analysis of clinical chemical parameters from the medical intensive care unit $(n=177)$ were kept frozen at $-70^{\circ} \mathrm{C}$ until analysis. Sera from critically ill patients with high levels of IL- 6 were pooled and aliquoted for linearity, stability and precision analysis. For comparison blood was collected from 30 healthy volunteers, centrifuged and kept frozen at $-70{ }^{\circ} \mathrm{C}$ until analysis.

Instrumentation and assay procedure

The assay was performed on a Roche Diagnostic System Cobas Core ${ }^{\circledR}$ immunological analyzer. The program parameters were set as outlined in Table 1. Capture antibody coated beads 
Tab. 1 Program parameters of Cobas Core ${ }^{\circledR}$ used for IL-6 determination.

\begin{tabular}{|c|c|c|c|c|}
\hline General & & Std. 4 & \multicolumn{2}{|c|}{853.0} \\
\hline Test name & IL-6 & Std. 5 & \multicolumn{2}{|c|}{1749.0} \\
\hline Kit size & 100 & Std. 6 & \multicolumn{2}{|c|}{2815.0} \\
\hline Reaction mode & 1-step & Standard replicate & \multicolumn{2}{|c|}{ Duplicate } \\
\hline Calibration mode & Lin Interpol & Kit control & \multicolumn{2}{|l|}{ Off } \\
\hline Decimal position & 1 & & & \\
\hline Std/CS-K unit (Kit) & $\mathrm{pg} / \mathrm{ml}$ & \multicolumn{3}{|l|}{ Calculation } \\
\hline Sample/CS Unit (Lab) & $\mathrm{pg} / \mathrm{ml}$ & \multicolumn{3}{|l|}{ Replicate Dev: } \\
\hline Unit factor & 1.0000 & Std. 1 & \multicolumn{2}{|l|}{ No } \\
\hline & & Std. 2 & \multicolumn{2}{|l|}{ No } \\
\hline Analytical & & Conversion factor & \multicolumn{2}{|c|}{1.0000} \\
\hline Replicate sample/CS & Single & Offset & \multicolumn{2}{|c|}{0.0000} \\
\hline Immuno reaction 1 time & $30 \mathrm{~min}$ & Test range: & \\
\hline Volume of & & Low Std. 1 & \multicolumn{2}{|c|}{ Nominal pg/ml } \\
\hline CS/Sample & $200 \mu \mathrm{l}$ & High Std. 2 & \multicolumn{2}{|c|}{ Nominal pg/ml } \\
\hline Standard & $200 \mu \mathrm{l}$ & Abnormal limit low & \multicolumn{2}{|c|}{ No $\mathrm{pg} / \mathrm{ml}$} \\
\hline Reagent 1 & $100 \mu \mathrm{l}$ & Warning limit low & \multicolumn{2}{|c|}{ No pg/ml } \\
\hline Dilution factor & Undil & Warning limit high & \multicolumn{2}{|c|}{ No $\mathrm{pg} / \mathrm{ml}$} \\
\hline Factor 1 & No & Abnormal limit high & \multicolumn{2}{|c|}{ No pg/ml } \\
\hline Factor 2 & No & & & \\
\hline Factor 3 & No & Assign & & \\
\hline \multirow{2}{*}{ Default Dilution } & Undil & Beads & B & Label 1 \\
\hline & & Reagent 1 & G & 2 \\
\hline Calibration & & Std 1 & $\mathrm{H} 1$ & $3 A$ \\
\hline Calibration interval mode & On Request & Std 2 & $\mathrm{H} 2$ & 3B \\
\hline No. of Standards & 6 & Std 3 & $\mathrm{H} 3$ & $3 C$ \\
\hline Nominal conc: & & Std 4 & $\mathrm{H} 4$ & $3 D$ \\
\hline Std. 1 & 0.0 & Std 5 & H5 & $3 \mathrm{E}$ \\
\hline Std. 2 & 35.0 & Std 6 & $\mathrm{H} 6$ & $3 F$ \\
\hline Std. 3 & 442.0 & & & \\
\hline
\end{tabular}

and detection antibody were added simultaneously and incubated for 30 minutes. After the addition of chromogenic reagent and incubation for 15 minutes, measurements were performed photometrically at a wavelength of $450 \mathrm{~nm}$. Six standards containing $0,35,442,853,1749$ and $2815 \mathrm{pg} / \mathrm{ml}$ of recombinant IL-6 were used for calibration. IL-6 measurements on microtiter plates were performed with the enzymelinked immunosorbent assay (ELISA, Biosource GmbH Ratingen, Germany) as recommended by the supplier. Measurements with the Cobas Core ${ }^{\circledR}$ were performed singly, while all measurements with microtiter plates were performed in duplicate.

\section{Statistics}

Descriptive data are given as mean \pm standard deviation. The reproducibility of the test was evaluated by measurement of recombinant, lyophilized controls and pooled patient sera repeatedly on the same day (intra-assay variation) or on different days (inter-assay variation). Linearity was determined with serum from patients with high levels of IL- 6 which was diluted with serum without detectable IL-6 and also with the highest standard containing $2815 \mathrm{pg} / \mathrm{ml}$ recombinant IL-6. Linear regression analysis was performed and Pearson's rank correlation coefficient determined for linearity analysis. For method comparison Passing-Bablok regression was performed and Kendall's Tau coefficient was determined (11).

\section{Results}

\section{Calibration curve and linearity}

A typical standard curve obtained by Cobas Core ${ }^{\circledR}(A)$ and the microtiter plate assay $(B)$ is shown in Figure 1.
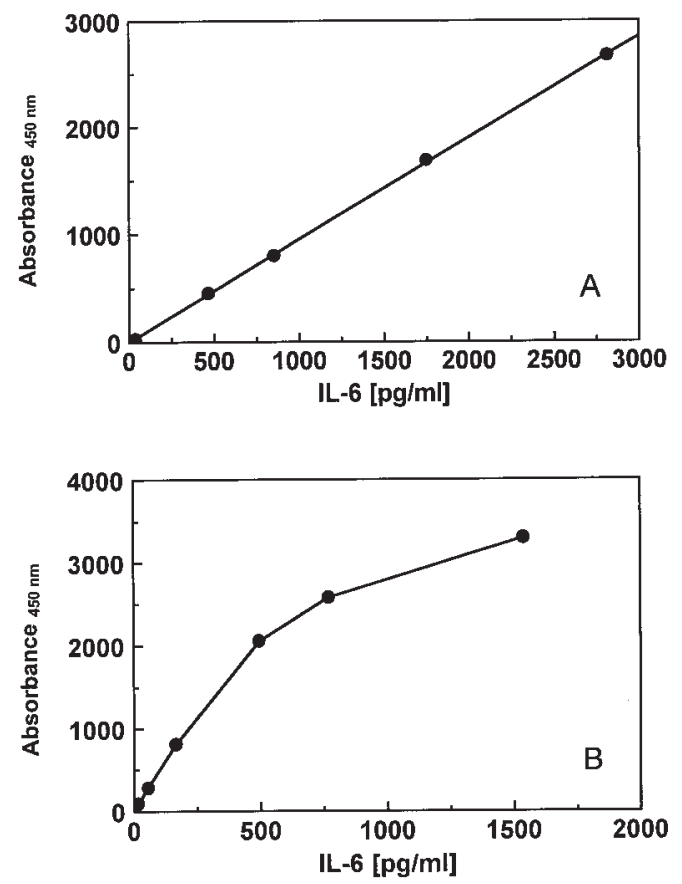

Fig. 1 Typical standard curves for the automated assay (A) and the ELISA on microtiter plate (B). 
Absorbance response to IL-6 concentration measured using the Cobas Core ${ }^{\circledR}$ assay is expressed by the equation

$$
\begin{aligned}
& A_{450}=0.95057[I L-6]_{\text {Cobas Core }}{ }^{\circledR}+0.00291 \text { and } \\
& r^{2}=0.99982 .
\end{aligned}
$$

Dilution of the highest recombinant standard with serum without detectable IL-6 showed a linear response up to $2815 \mathrm{pg} / \mathrm{ml}$ IL-6. In addition, sera of 4 patients with various IL-6 levels were diluted 1:2, 1:4 and 1:8 with serum without detectable IL-6. Recovery ranged between 102 and $117 \%$ indicating a good linearity throughout the calibration range.

\section{Precision}

Recombinant lyophilized controls $\mathrm{K} 1$ and $\mathrm{K} 2$ containing 124 and $286 \mathrm{pg} / \mathrm{ml} \mathrm{IL-6}$ and four pools P1, P2, P3 and P4 were used for precision analysis. Mean IL-6 levels of these pools were $\mathrm{P} 1=2.0 \pm 0.2, \mathrm{P} 2=128.9 \pm 5.5$, $\mathrm{P} 3=267.6 \pm 11.7$ and $\mathrm{P} 4=1070 \pm 24.4 \mathrm{pg} / \mathrm{ml}$, respectively. Within-run CV's for the lyophilized controls $\mathrm{K} 1$ and $\mathrm{K} 2$ with the automated method were 3.0 and $4.4 \%(n=10)$, and the between-run CV's were 5.5 and $4.1 \%$, (each $\mathrm{n}=25$ ), respectively. Measurement of the four pools revealed within-run CV's of $14.4(n=10), 3.6(n=10), 5.3$ $(n=10)$, and $2.3(n=8) \%$ and between-run CV's of 10.9 $(n=10), 4.3(n=25), 4.1(n=25)$, and $2.3(n=10) \%$, respectively.

\section{Accuracy}

Figure 2 shows the results of a dilution experiment of the NIBSC reference material $(2500 \mathrm{pg} / \mathrm{ml})$ with a serum sample without detectable IL-6. The regression line over the whole measuring range was defined by the equation

\section{IL-6 [Cobas Core $\left.{ }^{\circledR}\right]=1.012[$ NIBSC standard] - 21.9.}

The correlation coefficient was $r=0.9987$. The recovery of the IL- 6 standard was between 92.5 and $102.4 \%$. In addition 3 sera with various IL-6 levels were spiked with three different concentrations of NIBSC standard (250, 500 and $1000 \mathrm{pg} / \mathrm{ml})$. The recovery of IL-6, which

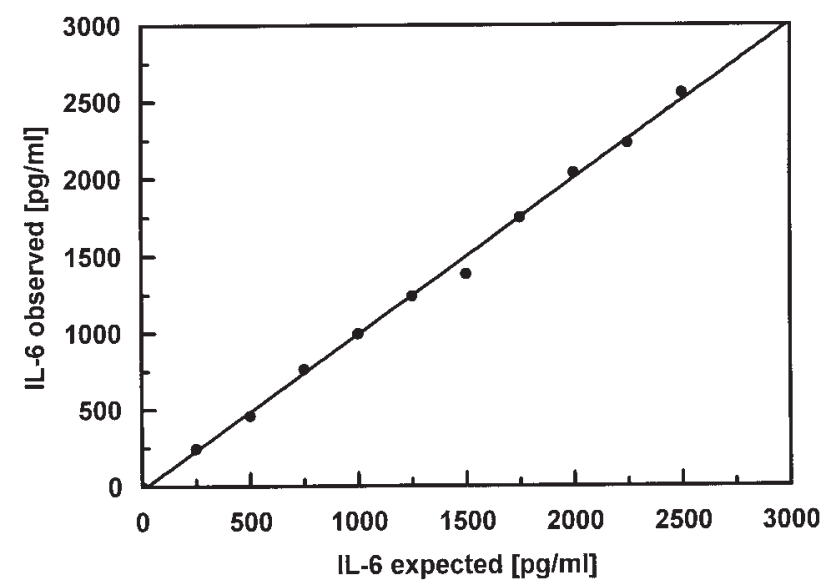

Fig. 2 Dilution recovery of 2500 pg/ml IL-6 (NIBSC, preparation 89/548). Dilution was performed with serum of a healthy control without detectable IL-6. varied between 90 and $109 \%$ (Tab. 2), indicates accurate measurement of IL- 6 with the automated assays.

Tab. 2 Spiking recovery of recombinant IL-6 standard (NIBSC) in sera of patients with various IL- 6 concentrations.

\begin{tabular}{lrrrr}
\hline Sample & $\begin{array}{c}\text { Spiking } \\
\text { amount }\end{array}$ & Expected & Observed & $\begin{array}{l}\text { Recovery } \\
(\%)\end{array}$ \\
\hline 1 & - & - & 1070 & \\
& 250 & 1317 & 1346 & 102 \\
& 875 & 1879 & 1882 & 100 \\
& 1750 & 2636 & 2441 & 93 \\
& & & & \\
2 & - & - & 522 & \\
& 250 & 770 & 837 & 109 \\
& 875 & 1350 & 1423 & 105 \\
& 1750 & 2123 & 1914 & 90 \\
& & & & \\
& - & - & 264 & \\
& 250 & 513 & 559 & 109 \\
& 875 & 1100 & 1172 & 106 \\
& 1750 & 1946 & 1930 & 99 \\
& & & & \\
4 & - & - & $<1.5$ & \\
& 250 & 249 & 235 & 94 \\
& 875 & 847 & 831 & 98 \\
& 1750 & 1637 & 1669 & 102 \\
\hline
\end{tabular}

\section{Stability}

Twenty samples were kept at $4{ }^{\circ} \mathrm{C}$ for 24 hours and showed no significant decrease of serum IL-6. In addition 27 samples were measured immediately after collecting them and then frozen for 72 hours at $-18^{\circ} \mathrm{C}$. No significant loss of activity could be observed after thawing.

\section{Method comparison}

For comparison with the microtiter plate assay serum samples of 130 patients with IL-6 levels up to 1000 $\mathrm{pg} / \mathrm{ml}$ from the intensive care unit were measured with

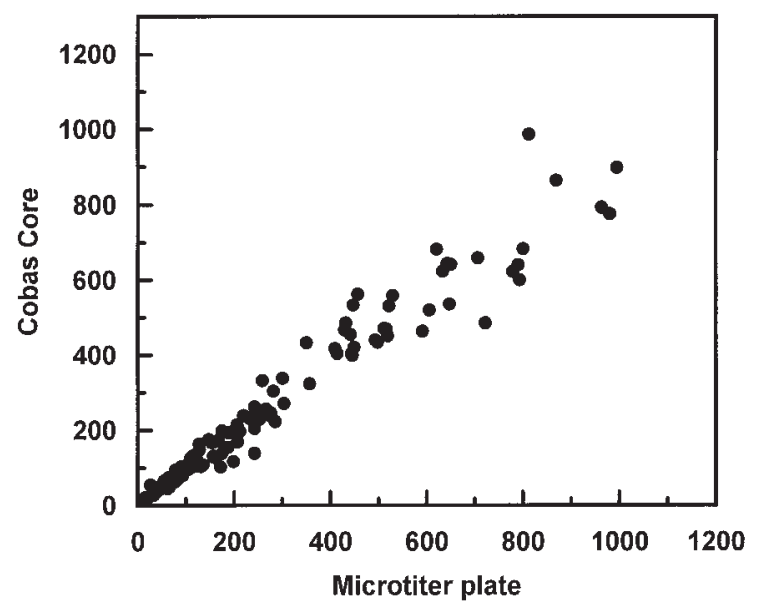

Fig. 3 Correlation between measurements of IL-6 (pg/ml) performed with the ELISA on microtiter plate and the automated assay on Cobas Core $^{\circledR}$. 
Cobas Core ${ }^{\circledR}$ and microtiter plate. The regression equation was defined by

$$
\begin{aligned}
& \mathrm{IL}-6_{\text {CobasCore }}=0.92 \mathrm{IL}-6_{\text {microtiterplate }}+5.32 \mathrm{pg} / \mathrm{ml} \\
& \text { and } \tau=0.9062
\end{aligned}
$$

(Fig. 3).

\section{Detection limit}

Detection limit, which is defined as the mean IL- 6 value of 20 repeat measurements of zero standard plus 2 standard deviation was $1.5 \mathrm{pg} / \mathrm{ml}$.

\section{Values of healthy controls}

In sera from 20 out of 30 healthy controls, IL-6 levels were below the detection limit of $1.5 \mathrm{pg} / \mathrm{ml}$. The $10 \mathrm{re-}$ maining controls had IL- 6 levels between 1.7 and $8.4 \mathrm{pg} /$ $\mathrm{ml}$. Mean IL-6 levels of all healthy controls were $2.1+1.8$ $\mathrm{pg} / \mathrm{ml}$.

\section{Discussion}

We here report for the first time an analytical evaluation of an automated IL- 6 assay. Measurements of IL- 6 performed routinely on microtiter plates have suggested that this cytokine may be a suitable early laboratory parameter during inflammatory processes. Reliable and quick measurement of IL- 6 levels may be useful in diagnostic and therapeutic decisions. However, for this purpose its serum level must be available daily and within a few hours. Measurement of IL- 6 on microtiter plates is time consuming and expensive when run in small series and therefore usually not available on the same day. The automated method evaluated in this study requires about 1 hour, which offers the possibility for measurement of IL-6 in a random access mode. Together with the operating characteristics of Cobas Core (throughput of 150 samples per hour, good user friendlyness), which has been investigated in detail $(12,13)$, automated measurement of IL-6 can be recommended for routine laboratories.

Although using single determinations, the imprecision of the automated method was in general below $6 \%$. In the lowest concentration pool, which was close to the detection limit, a CV up to $14.4 \%$ was found. This may still be acceptable. In contrast to the microtiter plate assay, this precision allows a single measurement saving time and sample volume. In the present study, the automated assay on the Cobas Core ${ }^{\circledR}$ was linear up to concentrations of $2815 \mathrm{pg} / \mathrm{ml}$. In contrast, in the microtiter plate ELISA, the absorbance response was linear up to only about $400 \mathrm{pg} / \mathrm{ml}$. The correlation coefficient between the manual and the automated assay was $r^{2}=0.8745$ up to concentrations of $400 \mathrm{pg} / \mathrm{ml}$ and $r^{2}=0.6751$ for values above $400 \mathrm{pg} / \mathrm{ml}$. Linearity over a wide range of standards permits the use of the automated assay for serum samples with IL- 6 levels over $1000 \mathrm{pg} / \mathrm{ml}$ without any dilution step. This may be of importance since high levels in the range between 1000 and $2000 \mathrm{pg} / \mathrm{ml}$ are often encounted in severe inflammatory conditions such as sepsis and septic shock (3).
Most data on cytokines reported in the literature are difficult to compare because of great variations in the values. However, calibration with the international standard (NIBSC 89/548) may improve comparisons of various assays (14). With serial dilutions of the NIBSC standard we obtained a close correlation of measured values. This is in good agreement with previous studies showing a good correlation of the Medgenix microtiter plate ELISA assay, which uses the same antibodies and reagents, with the NIBSC standard (15). For this reason results obtained with the assay reported here are comparable with the Medgenix assay and probably also with other IL-6 assays, which are calibrated against the NIBSC standard.

One critical factor for routine analysis is the instability of analytes in serum samples (16). We did not find any significant changes in IL- 6 values when sera were stored at $4{ }^{\circ} \mathrm{C}$ for 24 hours or at $-30^{\circ} \mathrm{C}$ for several days. We did not test the stability at different temperatures or longer storage periods.

In summary, the automated IL-6 assay on Cobas Core ${ }^{\circledR}$ correlates well with the manual microtiter plate method and this finding justifies its use in the routine laboratory. Further clinical studies are necessary to clarify whether IL-6 measurement in a random access mode may be a useful tool as an early marker of inflammation and therapy control.

\section{References}

1. Akira S, Tag T, Kishimoto T. Interleukin- 6 in biology and medicine. Adv Immunol 1993; 54:1-57.

2. Buck C, Bundschu J , Gallati H, Bartmann P, Pohlandt F. Interleukin-6: a sensitive parameter for the early diagnosis of neonatal bacterial infection. Pediatrics 1994; 93:54-8.

3. Calandra T, Gerain J, Heumann D, Baumgartner J D, Glauser MP. High circulating levels of interleukin-6 in patients with septic shock: evolution during sepsis, prognostic value, and interplay with other cytokines. The SwissDutch 5 Immunoglobulin Study Group. Am J Med 1991; 91:23-9.

4. Steinmetz HAT, Herbertz A, Bertram M, Diehl V. Increase in interleukin-6 serum level preceding fever in granulocytopenia and correlation with death from sepsis. J Infect Dis 1995; 171:225-8.

5. Heney D, Lewis IJ , Evans SW, Banks R, Bailey CC, Whicher J T. Interleukin- 6 and its relationship to C-reactive protein fever in children with febrile neutropenia. J Infect Dis 1992; 165:886-90.

6. LeMoine O, Deviere J, Devaster J M, Crusiaux A, Durand F, Bernuau J , et al. Interleukin-6: an early marker of bacterial infection in decompensated cirrhosis. J Hepatol 1994; 20:819-24.

7. Damas P, Ledoux D, Nys M, Vrindts Y, De-Groote D, Franchimont $P$, et al. Cytokine serum level during severe sepsis in human IL-6 as a marker of severity. Ann Surg 1992; 215:356-62.

8. Goldie AS, Fearon KC, Ross J A, Barclay GR, J ackson RE, Grant IS, et al. Natural cytokine antagonists and endogenous antiendotoxin core antibodies in sepsis syndrome. The Sepsis Intervention Group. J Am Med Assoc 1995; 274:172-7.

9. Rosenbloom AJ, Pinsky MR, Bryant J L, Shin A, Tran T, 
Whiteside T. Leukocyte activation in the peripheral blood of patients with cirrhosis of the liver and SIRS. Correlation with serum interleukin-6 levels and organ dysfunction. J Am Med Assoc 1995; 274:58-65.

10. Gaines Das RE, Poole S. The international standard for interleukin-6. Evaluation in an international collaborative study. J Immunol Methods 1993; 160:147-53.

11. Passing H, Bablock W. Application of linear regression procedures for method comparison studies in clinical chemistry, Part II. J Clin Chem Clin Biochem 1988; 26:783-90.

12. Renard C, Cheminel V, Prevosto J M, Soares O, Chaulet J F. Cobas ${ }^{\circledR}$ Core II: evaluation of analytical performance and integration in the endocrine and tumor marker laboratory. Clin Lab 1997; 43:834-55.

13. Kötting J , Heinemann G, Salb I, Maier-Lenz H. Evaluation of the Cobas Core II immunochemistry analyser. J Autom Chem 1996; 18:205-15.

14. Bienvenu J, Coulon L, Doche C, Gutowski MC, Grau GE.
Analytical performance of commercial ELISA-kits for IL-2, IL-6 and TNF- $\alpha$. A WHO study. Eur Cytokine Netw 1993; 4:447-51.

15. Ledur A, Fitting C, David B, Hamberger C, Cavaillon J M. Variable estimates of cytokine levels produced by commercial ELISA kits: results using international cytokine standards. J Immunol Methods 1995; 186:171-9.

16. Thavasu PW, Lonhurst S, J oel SP, Slevin ML, Balkwill FR. Measuring cytokine levels in blood. J Immunol Methods 1992; 153:115-24.

Received 8 April 1998; accepted 21 August 1998

Corresponding author: Dr. med. Peter Fraunberger, Institut für Klinische Chemie, Klinikum Grosshadern, Ludwig Maximilians Universität München, Marchioninistr. 15, D-81366 Munich, Germany

Tel.: +49 89 7095-3234, Fax: +49 8970958888 
Vakat 